\title{
OS "NOVOS" EDUCADORES DOS PROGRAMAS DE EDUCACTÃO INTEGRAL: UMA ANÁLISE DAS PRÁTICAS EDUCATIVAS DOS AGENTES CULTURAIS
}

\author{
Juarez Dayrell \\ Faculdade de Educação da Universidade Federal de Minas Gerais (FaE-UFMG) \\ Saulo Geber** \\ Psicologia - Pontifícia Universidade Católica do Paraná (PUCPR)
}

RESUMO: O presente artigo discute os resultados de uma pesquisa que buscou compreender a inserção de novos perfis profissionais em experiências de Educação Integral pública brasileira. Muitos programas vêm contratando Agentes Culturais para desenvolver atividades educativas na expansão do tempo escolar. Os saberes trabalhados em suas oficinas não se limitam aos conteúdos acadêmicos curriculares e, em alguns casos, são resultado de vivências prévias desses sujeitos em grupos culturais e movimentos sociais. Esses educadores, que muitas vezes são jovens e moradores das comunidades próximas às escolas, acabam também estabelecendo uma relação de proximidade e afetividade com seus educandos. Este trabalho defende a tese de que a relação entre agentes e alunos cumpre uma importante função formativa na prática desses profissionais. Por meio dessa relação, os agentes mediam processos de aprendizagem, socialização, sociabilidade e desenvolvimento na formação integral de seus educandos. Palavras-chave: Novos educadores. Educação Integral. Prática educativa.

http://dx.doi.org/10.1590/0102-4698151322

"Doutor em Educação pela Faculdade de Educação da USP. Professor Associado da Faculdade de Educação da UFMG e do Programa de Pós-Graduação. Pesquisador do CNPq e coordenador do Grupo de Pesquisa Observatório da Juventude da UFMG. Email: juareztd@gmail.com

"*Doutor em Educação pela Faculdade de Educação da UFMG. Professor do curso de Psicologia da PUCPR. Integrante do Observatório da Juventude da UFMG. Email: saulopgeber@gmail.com 
THE "NEW" INTEGRAL EDUCATION PROGRAM'S EDUCATORS: CULTURAL AGENT'S EDUCATIONAL PRACTICES ANALYSIS

ABSTRACT: This paper discusses results of a study that sought to understand the inclusion of new professional profiles in Brazilian public Integral Education experiences. Many programs are hiring Cultural Agents to develop educational activities in the expansion of school time. The knowledge worked in their workshops were not limited to curricular academic content and, in some cases, are the result of previous experiences of these subjects in cultural groups and social movements. These teachers, who are often young and residents of communities near schools, also end up establishing an affective and close relationship with their students. This work defends that the relationship between Agents and students plays an important formative role in the practice of these professionals. It is through this relationship that Agents mediate learning processes, socialization, sociability and development in the integral formation of its students.

Keywords: New educators. Integral education. Educational practice.

\section{INTRODUCุ̃̃O}

Nos últimos anos, temos acompanhado a crescente expansão da política de Educação Integral pública brasileira. Em muitas das experiências, o aumento da carga horária escolar vem ocorrendo junto a uma proposta de ressignificação da concepção educativa na direção de uma formação mais integral dos sujeitos (GUARÁ, 2007; ARROYO, 2012). Essa perspectiva parte de pressupostos como uma maior diversificação do currículo e uma maior aproximação à realidade local dos educandos e suas respectivas comunidades (MOLL, 2008). Para Evaristo et al. (2008), a ampliação da proposta educativa vem demandando pensar novos saberes, práticas, tempos e espaços formativos. Nessa perspectiva, muitas experiências vêm incorporando conhecimentos e práticas que tradicionalmente, até então, não faziam parte do cotidiano escolar.

Outra inovação presente nas experiências de Educação Integral no Brasil refere-se à presença de um novo perfil de educadores. Em uma pesquisa nacional, em que foram analisados cerca de 800 programas de Educação Integral do país, constatou-se que muitos programas vêm contratando novos perfis profissionais ${ }^{1}$ para atuarem como educadores em programas de Educação Integral (BRASIL, 2009).

Esses educadores atuam em condições diversas e recebem denominações diferenciadas, como Agentes Culturais, Monitores, 
Oficineiros, Mediadores Sociais etc. Nessa diversidade, algumas características tendem a se repetir. A referida pesquisa do MEC (BRASIL, 2009) mostrou que esses educadores são responsáveis pelo desenvolvimento de uma rica diversidade de atividades durante a jornada ampliada. Entre elas, podemos citar esportes, aula de reforço, música, dança, teatro, informática, oficinas temáticas, artesanato, para casa, artes plásticas, artes visuais, capoeira, rádio e jornal (BRASIL, 2009).

Os saberes trabalhados em suas oficinas não se limitam aos conteúdos acadêmicos curriculares e, em alguns casos, são resultado de vivências prévias desses sujeitos em grupos culturais e movimentos sociais. Essa diversidade é expressão das constatações de Santos (2002) de que "a experiência social em todo o mundo é muito mais ampla e variada do que o que a tradição científica ou filosófica ocidental conhece e considera importante". (SANTOS, 2002, p. 2).

Como previsto em alguns dos programas de Educação Integral, é comum os Agentes Culturais ${ }^{2}$ serem moradores ou possuírem algum tipo de vínculo com as comunidades próximas às escolas onde as atividades ocorrem, conhecendo, por isso, os alunos, seus familiares, o bairro e os aspectos da cultura local. Existe, também, uma recorrência maior de jovens, entre eles ex-alunos das próprias escolas onde atuam. Esses fatores possibilitam que os agentes pesquisados estabeleçam um diálogo entre os alunos, a escola e a comunidade, em um trabalho de mediação social (DUBET, 2006; CARVALHO; DAYRELL; GEBER, 2012).

Em artigo recente, Carvalho, Dayrell e Geber (2012) discutem que esses Agentes Culturais, agindo como mediadores sociais entre a escola e os alunos, tendem a criar pontes de tradução entre a cultura hegemônica, expressa nas políticas públicas, e a cultura local das comunidades, alvo dessas políticas. Por um lado, seriam capazes de compreender as demandas e os interesses das políticas públicas, seus propósitos e objetivos, e, por outro, teriam trato para trabalhar com as crianças e os jovens nas escolas, possuindo histórias de vida semelhantes às deles, conhecendo a realidade onde estão inseridos, seus locais de moradia, e estabelecendo com eles uma relação dialógica (CARVALHO; DAYRELL; GEBER, 2012).

Até então, esses sujeitos e as especificidades e sentidos de suas práticas em programas de Educação Integral não têm sido alvo de pesquisas, reflexões e debates. Esse contexto nos instigou a realizar uma pesquisa buscando compreender as práticas educativas desses agentes ${ }^{3}$. A investigação, ainda em curso, procura responder algumas das seguintes perguntas: o que tem caracterizado as práticas educativas desses agentes? 
Quais são as estratégias e metodologias utilizadas por eles no cotidiano escolar? Para além de novos saberes, esses sujeitos também estariam alterando a forma de organização do conhecimento escolar? Se sim, de que forma? Neste artigo, buscaremos responder algumas dessas questões.

Para tanto, foram selecionados agentes cujas práticas fossem avaliadas como promissoras e que poderiam nos dar direcionamentos de novos caminhos de atuação profissional em contextos de Educação Integral. Este artigo representa um primeiro exercício de sistematização dos dados coletados e de indicadores de potenciais práticas educativas de Agentes Culturais que vêm desenvolvendo trabalhos efetivos na direção da formação integral de crianças e jovens.

\section{A PRÁTICA EDUCATIVA}

Os Agentes Culturais são contratados pelos programas de Educação Integral para a realização de oficinas culturais, esportivas e de reforço escolar durante a jornada estendida. Em nossas observações, foi possível constatar que o contato dos agentes pesquisados com os alunos não se limita aos momentos dessas oficinas e que eles passam uma grande quantidade de tempo juntos nas oficinas, mas também nos horários de lanche, almoço, recreio, entrada e saída da escola e em muitos casos nos trajetos escola-casa dos alunos.

Muitas vezes, no tempo em que estão juntos, agentes e alunos se divertem fazendo brincadeiras ou contando piadas e histórias engraçadas. A participação nas atividades das oficinas, em muitos casos, não é imposta, mas de adesão voluntária dos alunos. Também é recorrente, nos contatos com os alunos, o diálogo sobre temáticas que extrapolam o habitual conteúdo das oficinas e da escola, como música, televisão, o que está acontecendo em seu bairro e também na cidade. É comum ver alunos contando para os agentes situações de seu cotidiano em suas relações com família, comunidade e amigos.

Ao serem questionados, muitos agentes pesquisados reforçam essa relação de proximidade com seus alunos e em muitos casos justificam suas práticas justamente a partir dessa relação: "Eu desenvolvi essa oficina porque os meninos gostam"; "Fui percebendo que essa era a melhor forma de trabalhar com eles"; "Eles adoram quando a gente faz algum trabalho e depois apresenta um produto para a escola"; "Os meninos vêm sempre conversar com a gente quando precisam de algum conselho ou quando estão passando por alguma situação difícil”.

Nas observações de campo e nas entrevistas realizadas com esses sujeitos, fica evidente a centralidade da relação entre agentes e 
alunos em suas práticas educativas. Essas observações empíricas nos fazem questionar: o que levou esses agentes a centrar suas práticas nas relações com seus educandos? Por que assumiram essa postura, que em parte difere de outros profissionais da educação?

\section{DA RELAC̣ÃO COM OS SUJEITOS}

Em pesquisas sobre formação de professores, tem sido comum a discussão sobre as dimensões formativas presentes na constituição dos docentes. Autores como Tardif (2002) e Gauthier (2006) identificam que professores recorrem a saberes de diferentes espaços na constituição de suas práticas profissionais. Eles apontam que boa parte da formação dos professores é resultado da vivência acadêmica, dos cursos de formação inicial e continuada e, também, das formações disciplinares e curriculares. Além dessa formação, os professores também se valem de suas vivências pessoais, como suas experiências escolares com alunos e os contatos com seus familiares e colegas de trabalho. Essas diferentes dimensões são articuladas e ressignificadas na prática cotidiana escolar dos docentes, que também se constituem como uma dimensão formativa.

No entanto, diferentemente do que ocorre com outros profissionais da educação, a prática dos Agentes Culturais pesquisados tende a não estar alicerçada em uma formação acadêmica específica, nem mesmo em parâmetros profissionais estipulados por normas e costumes. Os conteúdos trabalhados também tendem a ser mais flexíveis, se comparados às exigências postas aos professores do ensino regular.

Possivelmente, por essa pouca prescrição e referência externa, muitos desses agentes têm centrado suas práticas educativas na relação com seus educandos. É através do contato e da relação estabelecidos com os alunos que os agentes tendem a criar e organizar suas atividades.

Essa constatação nos faz refletir sobre a dimensão das relações sociais, aspecto pouco analisado em reflexões educacionais. $\mathrm{Na}$ realidade, com uma padronização crescente de currículos, práticas de ensino e avaliações, a reflexão sobre a dimensão das relações intersubjetivas vem perdendo cada vez mais espaço. Para Robinson (2011), a homogeneização dos espaços educativos tende a fazer com que deixemos de lado as singularidades dos sujeitos reais e as interações que eles estabelecem no cotidiano das escolas.

No entanto, para a pesquisadora Inês Teixeira (2007), a relação professor/aluno é fundante e constitutiva da condição docente. É por 
meio da relação com seus alunos que os professores se constituem: "Um não existe sem o outro. Docentes e discentes se constituem, se criam e recriam mutuamente, numa invenção de si que é também uma invenção do outro. Numa criação de si porque há o outro, a partir do outro". (TEIXEIRA, 2007, p. 429).

Apesar da pouca atenção dada às relações educativas, essa dimensão ocupou lugar de destaque nos resultados de duas pesquisas desenvolvidas com alunos de escolas públicas de diferentes estados brasileiros (DAYRELL; LEÃO; REIS, 2011a; DAYRELL; LEÃO; REIS; 2011b; DAYRELL; JESUS, 2013). Para os autores dessas pesquisas, a escola tem sido vista pelos jovens como espaço privilegiado de relações, tanto com os amigos ${ }^{4}$ quanto com os professores, evidenciando a centralidade do reconhecimento intersubjetivo para a construção e o reforço da autoconfiança. Os depoimentos dos alunos tendem a reconhecer a relação com o professor como condição de aprendizagem, como nos diz uma jovem de Belo Horizonte: "Primeiramente o professor tem que se dar bem com os alunos, se não, ele não consegue dar aula". (DAYRELL; JESUS, 2013, p. 26).

Em outro exemplo, em uma pesquisa encomendada pelo governo norte-americano, o pesquisador Hirsch (2005) deveria avaliar o impacto do Programa Smart Girls. Esse programa objetivava trabalhar questões de gênero e sexualidade com meninas em idade escolar. As escolas recebiam um material didático com metodologia, dinâmicas, textos de apoio, músicas, vídeos etc. Hirsch (2005) constatou que grande parte do impacto do programa estava nas relações que as alunas estabeleciam com as educadoras responsáveis, e não tanto na metodologia em si. Para o autor, tão importante quanto a metodologia do programa, era o vínculo criado pelos sujeitos em suas práticas.

Nos relatos de campo apresentados pelo pesquisador, em algumas escolas, as jovens procuravam as educadoras para contar suas vivências e seus dilemas, abordando aspectos de seus corpos, de suas relações com seus namorados e suas famílias. Essas educadoras, em muitas situações, alteravam as propostas metodológicas para atender às especificidades de demandas das jovens com quem estavam trabalhando.

As pesquisas aqui citadas exemplificam o papel que a relação intersubjetiva ocupa nas práticas educativas de forma específica e na interação entre os sujeitos de forma geral. É importante, no entanto, reconhecer que as relações entre os sujeitos ocorrem em contextos específicos (TEIXEIRA, 2007), assumindo diferentes dimensões, características, expressões e conteúdos (DEUTSCH; DUBOIS; 
HIRSCH, 2011). Apresentaremos a seguir alguns modelos de relação de crianças e jovens com algumas figuras de adultos, entre eles os pais, os professores e os profissionais da Assistência Social e Saúde.

A relação de crianças e jovens com seus pais normalmente é centrada nas dimensões não escolares, como aspectos afetivos, morais e culturais. Os pais, principalmente os de famílias pobres, intervêm pouco na formação acadêmica de seus filhos. Além disso, a interação entre pais e filhos tem diminuído nas últimas décadas em decorrência das demandas do mundo do trabalho para a população pobre. As extensivas jornadas, inclusive aos finais de semana, e o tempo gasto com a locomoção vêm diminuindo o tempo de relação de pais trabalhadores com seus filhos.

Por sua vez, crianças e jovens passam bastante tempo se relacionando com seus professores. No entanto, a característica dessa relação é a centralidade das disciplinas e dos conteúdos. Segundo Deutsch, DuBois e Hirsch (2011), a escola, com sua estrutura departamentalizada, acaba por ter como resultado professores mais comprometidos com seus conteúdos do que com seus estudantes. Para os autores, os professores não conseguem conhecer seus alunos, nem preencher as necessidades dos adolescentes por relações significativas com os adultos.

Uma terceira figura adulta estaria na relação de crianças e jovens com profissionais dos programas de assistência social e de saúde. Médicos, enfermeiros, psicólogos e assistentes sociais são alguns dos profissionais dessas relações, que tendem a ser pontuais, ocorrendo de forma esporádica. O pouco contato não permite às crianças e aos jovens criar relações de confiança com esses profissionais. Além disso, a dimensão identitária dessas relações tende a ser pouco atrativa para as crianças e os jovens, já que boa parte delas é mediada pela concepção de doente, vulnerável ou mesmo perigo.

As diferentes relações de crianças e jovens com adultos cumprem uma importante função para o desenvolvimento e a formação dos sujeitos. A relação é mediadora dos processos de aprendizagem, socialização, sociabilidade e desenvolvimento de uma forma geral. No entanto, podemos constatar que boa parte das relações existentes entre as crianças e jovens com as figuras de adultos vem se caracterizando por ações focais e específicas em determinadas dimensões, como a afetiva, a acadêmica ou mesmo a preventiva.

A questão que se coloca neste artigo é a da possibilidade de relações formativas integrais de crianças e jovens com adultos. Os 
avanços conceituais realizados, em que se propõe uma Educação Integral que reconheça os educandos como sujeitos com dimensões cognitivas, sociais, afetivas e relacionais (GUARÁ, 2007), não deveriam também pensar práticas profissionais que se direcionem para essa integralidade?

Tendemos a acreditar que os Agentes Culturais investigados, em suas práticas, a partir das relações com os alunos, têm adotado posturas interventivas que se direcionam a uma maior integralidade das relações. Possivelmente, essa postura é resultado de uma menor adesão desses "novos" profissionais aos modelos correntes de relação pedagógica e de aprendizagem. A seguir apresentaremos algumas das dimensões dessas relações que vêm sendo observadas em nossa pesquisa e que acreditamos ser promissoras ${ }^{5}$.

\section{AS RELAC̣̃̃ES EM UMA FORMAC̣ÃO INTEGRAL}

Os Agentes Culturais, por meio das relações que estabelecem com seus educandos, vêm constituindo novas práticas educativas que se direcionam em uma perspectiva de formação integral dos sujeitos. Essas estratégias vêm sendo construídas em suas práticas cotidianas em decorrência das relações que eles constroem com seus alunos, como vimos, devido, em parte, a uma não identificação com modelos e práticas educativas comumente instauradas.

Nas observações da pesquisa, foi possível constatar que a relação entre agentes e alunos muitas vezes é permeada por um clima de diversão e descontração. É interessante perceber que "se divertir" raramente surge como objetivo de propostas educacionais. Assim, a diversão não é tida como a prioridade dos currículos e das concepções pedagógicas, no entanto, essa dimensão parece ser de importância central nas vivências cotidianas de crianças e jovens. Rir, contar piadas, fazer brincadeiras uns com os outros é uma constante nas interações desses sujeitos.

Tendemos a acreditar que os agentes utilizam essa estratégia para criar vínculos com seus alunos. Ao perceberem que essa dimensão é importante para eles, nos parece que a utilizam para se aproximar e criar uma relação de confiança.

Além de divertida, a relação tende a ser afetuosa. Os abraços e as manifestações de carinho, incomuns e muitas vezes criticados no ambiente escolar, são constantes nas práticas desses agentes. Os alunos parecem expressar uma "carência afetiva". Carência essa que não corresponde às imagens preconceituosas sobre as crianças e os 
jovens das camadas populares, mas que é constitutiva do ser humano, que tem corpo, emoções, desejos e necessidades, aspectos esses que por muito tempo foram deixados de lado por uma educação que se centra na racionalidade e no intelecto.

Em uma perspectiva de formação integral dos sujeitos, os agentes pesquisados parecem, também, destinar suas intervenções às relações afetivas. Inclusive, o contato afetivo parece se constituir como um momento de aprendizagem, de expressão de sentimentos e de definição de limites. Como relata um agente, "Eu falo com eles: 'Vocês podem vir me abraçar, mas não é para ficar me agarrando"'. Essa negociação nas relações afetivas demonstra que é possível expressar afetividade em ambientes e relações profissionais.

Estratégias similares às adotadas por esses agentes foram observadas em programas de orientação educacional nos EUA, nos quais tutores, antes de iniciarem as orientações pedagógicas, dedicavam um período de tempo às brincadeiras ou estabelecendo laços afetivos com seus alunos. Pesquisas vêm mostrando que os tutores que destinavam atenção para a criação desse vínculo, que é ao mesmo tempo afetivo e instrumental, obtiveram posteriormente um maior retorno dos alunos sobre o trabalho pedagógico realizado (RHODES, 2004; KELLER, 2005; NAKKULA; HARRIS, 2005).

\section{REFORÇO DE CONTEÚDOS ESCOLARES}

Em suas práticas, os agentes investigados destinam parte de suas ações para o reforço de conteúdos escolares. Muitas vezes, nas oficinas, eles dedicam momentos específicos para a realização e correção do para casa; em outras situações, alunos buscam esses agentes na hora do recreio ou no intervalo do almoço para sanar dúvidas sobre alguma atividade escolar ou para pedir ajuda para realizar alguma pesquisa sobre o tema de uma aula.

Nas oficinas, independente da temática, os conteúdos escolares são constantemente pontuados e reforçados por esses agentes. Durante uma oficina de construção de história em quadrinhos, por exemplo, o agente orienta o grupo no desenho dos personagens e também faz as correções gramaticais dos textos escritos pelos alunos. Em uma oficina de jogos, o exercício da matemática é constante: contar as peças, dividir as cartas entre o número de jogadores e fazer a somatória dos pontos ao final do jogo são alguns exemplos.

As observações vêm mostrando que as oficinas, apesar de não terem como tema central os conteúdos escolares, funcionam como um 
espaço de aprendizagem e reforço dos mesmos. No entanto, é importante destacar que, apesar de trabalhar os conteúdos acadêmicos, essa parece não ser a prioridade das oficinas. Segundo relatos de alguns desses agentes, eles acreditam que os conteúdos escolares já vêm sendo suficientemente trabalhados pelos professores em sala de aula, possibilitando, assim, que eles abordem outras temáticas que também seriam importantes para a formação e o desenvolvimento das crianças e dos jovens.

\section{NOVOS SABERES}

As oficinas não seguem um currículo rígido e nem se limitam aos conteúdos curriculares. São trabalhados conteúdos diversificados, abordando as dimensões da arte, cultura, esporte, tecnologias, meio ambiente, aspectos comunitários etc, de acordo com a temática de cada oficina.

Um fato característico e recorrente em diferentes experiências pesquisadas sobre as oficinas é que muitas delas trabalham temáticas que são de adesão e interesse dos alunos. As oficinas abordam temas atrativos aos alunos, que estimulam sua vontade de aprender e de participar. A dimensão do desejo é transversal em várias das oficinas observadas e explica, em parte, o interesse dos alunos em participar das práticas propostas.

É interessante destacar como o interesse pela temática da oficina reforça o vínculo de relação entre agentes e alunos. Os agentes são muitas vezes praticantes habilidosos das temáticas de interesse das crianças e dos jovens - são mestres de capoeira ou experientes em informática; conhecem as ferramentas tecnológicas da fotografia e do vídeo ou sabem desenhar e pintar, entre outros exemplos. Os alunos, muitas vezes, projetam no agente a personificação da pessoa habilidosa de um determinado saber e prática, um modelo a ser seguido, algo a ser alcançado. Em conversas informais, ouvimos os alunos dizendo: "Nossa, quero aprender a desenhar igual a você..." ou: "Um dia ainda vou jogar capoeira igual ao Mestre".

Guiadas pelo desejo, as oficinas constantemente são organizadas e planejadas para a execução de uma determinada atividade que gera um produto: pintar o muro do centro cultural, apresentar um programa de rádio para a escola, jogar em um campeonato de futebol do bairro, desenvolver uma campanha de combate à dengue na região. As ações das oficinas se destinam a um produto concreto, real e próximo à realidade dos alunos. Essa objetividade parece dar 
sentido às ações e responde às perguntas frequentes entre os jovens: por que estamos fazendo isso? Para que estamos aprendendo isso?

As aprendizagens tendem a ser adquiridas e acumuladas no percurso de desenvolvimento de um determinado produto. Em projetos futuros, as mesmas aprendizagens serão acessadas e novas serão construídas a partir dos problemas propostos. Em uma oficina de vídeo, por exemplo, alunos se debruçam sobre um notebook e aprendem a utilizar um programa de edição. As técnicas são ensinadas pelo agente na medida em que são necessárias para a execução de uma determinada tarefa. O próprio agente afirma: "Eu trabalho com edição há anos e até hoje não sei todas as ferramentas [...]. A gente vai aprendendo e ensinando para eles na medida que precisa resolver os problemas".

Ao serem indagados sobre a organização do ensino, os agentes investigados direcionam suas respostas para seus alunos. Eles reconhecem que desenvolveram essas práticas observando seus alunos e vendo quais eram as melhores estratégias para que eles aprendessem. É interessante constatar como esses educadores, de forma aparentemente intuitiva, chegaram a metodologias similares às propostas de ensino que centram sua atenção no protagonismo dos alunos, como a pedagogia de projetos por exemplo.

Pesquisas no campo educacional vêm reforçando cada vez mais uma crítica ao modelo instrucionista de ensino, centrado em um currículo previamente organizado, com conteúdos segmentados e de pouca participação e interferência dos alunos (SAWYER, 2012).

Como alternativa, autores de diferentes campos do conhecimento vêm valorizando as aprendizagens que consideram o desejo dos educandos (CHARLOT, 2000), que se aproximam das práticas sociais da realidade (LAVE; WENGER, 1991), que valorizam a construção de projetos que busquem a solução de problemas reais (KRAJCIK; BLUMENFELD, 2012) e entendam a aprendizagem como um processo contínuo de construção e reconstrução de habilidades (LARSON, 2000; GLADWELL, 2008).

Possivelmente, de forma análoga a esses pesquisadores que desenvolvem novas práticas de ensino a partir das observações realizadas com os alunos, os agentes pesquisados também vêm "inventando" novas formas de se ensinar, que se aproximam mais dos desejos, das demandas e dos interesses dos alunos.

\section{DESENVOLVIMENTO DOS SUJEITOS}

Segundo relatos dos agentes, o trabalho com os alunos nas oficinas não se limitam a apenas aos conteúdos. Um agente diz: 
"Gosto quando os alunos assumem responsabilidades; eu divido as tarefas e cada um fica responsável por uma parte. Ele sabe que, se ele não fizer sua parte, o trabalho vai ficar comprometido". Outro agente justifica a oficina de xadrez: "Eles trabalham concentração, estratégia, raciocínio. Através do Xadrez, busco ensinar o respeito também".

Muitos agentes justificam suas práticas a partir da aquisição de valores, competências e habilidades. Uma agente, retomando o próprio processo vivenciado por ela, reconhece a importância exercida pela Arte em sua formação subjetiva. A Arte, além de uma linguagem estética, pode ser um instrumento de reflexão e construção identitária e de mundo. Para esses agentes, em alguns momentos, tão importante quanto a aprendizagem de um saber ou conteúdo é a formação mais ampla dos sujeitos.

Tendemos a acreditar que esses profissionais, por meio de suas práticas, buscam atingir dimensões como o conhecimento de si, a autoestima, a socialização, a formação ética, identitária e racial, o caráter etc. Em suas práticas, os agentes, por meio das atividades, buscam incentivar dimensões como a autonomia dos participantes, o trabalho em equipe, a liderança, a persistência em cumprir um determinado objetivo, a autoestima e, também, a identidade. Nas atividades, em diversos momentos, é estimulado que os jovens cumpram papéis a que não estão acostumados, que se esforcem e que também assumam responsabilidades no desenvolvimento de alguma ação ou projeto. Foi possível constatar durante a observação que a valorização desses aspectos permeia constantemente as práticas dos educadores.

É importante destacar que essa valorização pelos agentes das dimensões "não cognitivas" também vem sendo incentivada e desenvolvida em diferentes experiências educativas (LARSON, 1993; MURNANE; LEVY, 1996). Para Larson (2000), a instituição escolar tem cumprido o papel de transmissão de conteúdos curriculares, no entanto, existe uma série de dimensões necessárias para o preparo à vida adulta que não têm sido focalizadas pelas escolas, como a formação identitária, a iniciativa, o trabalho em grupo, a persistência, a motivação etc. Segundo o autor, essas dimensões raramente são consideradas ou avaliadas nas práticas educativas. Os testes educacionais normalmente medem conhecimentos e procedimentos, avaliando as aprendizagens dos alunos, no entanto, eles não conseguem captar se as escolas estão fazendo com que os alunos se tornem mais responsáveis, éticos, respeitosos.

A linguista Shirley Heath (1999) desenvolveu um estudo comparado entre jovens que participavam de oficinas formativas em programas de ampliação da jornada escolar e outros que não 
participavam. Após um período de observação, a autora constatou que o grupo que participava das atividades havia apresentado mudanças significativas na forma de organização e apresentação de ideias. A análise de gravações de conversas mostrou que os alunos começaram a utilizar condicionantes em suas frases, estabelecendo relações de causa e consequência, formulando hipóteses e projetando consequências futuras. Já, as frases dos alunos que não participavam das ações estavam mais centradas ao momento presente e tendiam a não relativizar as informações trabalhadas.

\section{O CUIDADO}

Um último aspecto consiste em uma dimensão de cuidado presente na relação estabelecida entre agentes e alunos. Em muitas situações, esses profissionais são procurados por alunos que lhes confessam alguma situação que estão vivenciando. Os relatos vão desde sentimentos não correspondidos por algum colega da escola a problemas que vivenciam em suas casas. Pela proximidade que estabelecem, muitas vezes os agentes são os primeiros a constatar e a denunciar situações de violência sofridas pelos alunos. Um dos agentes pesquisados, por exemplo, desenvolve um trabalho em parceria com o posto de saúde, encaminhando alunos que estejam doentes ou que precisam fazer algum exame, como o oftalmológico. Durante um recreio na escola, ele nos mostrou diversos alunos que começaram a usar óculos depois que o agente percebeu suas dificuldades.

A relação do cuidado parecer ser potencializada pela proximidade existente entre agentes e alunos. Como vimos, eles passam bastante tempo juntos, muitas vezes moram no mesmo bairro, possuem interesses em comum e compartilham algumas experiências. Uma agente diz: "O tiro que ele escuta de noite eu também escuto", reconhecendo as dificuldades de morar em uma região com ocorrências de violência. Muitos agentes conhecem os familiares dos alunos, encontrando-os pelo bairro e conversando.

O trabalho de mediação dos agentes não se limita aos alunos e aos horários da escola. Eles vivem na mesma região, fazem compra nos mesmos mercados, pegam os mesmos ônibus e vivenciam realidades parecidas. Além da dimensão etária, existe a proximidade geracional, eles geralmente gostam dos mesmos grupos musicais, assistem aos mesmos programas de televisão e se divertem com os mesmos jogos de computador. Essa proximidade e esses elementos em comum, muitas vezes, possibilitam estabelecer as pontes de diálogo e a intervenção entre agentes e alunos. 
Como vem sendo apresentado, as práticas educativas dos Agentes Culturais abordam diferentes dimensões formativas. Essa característica as diferencia das usuais relações de crianças e jovens com figuras de adultos, como pais e professores, que, em muitos casos, tendem a se centrar em dimensões específicas como o cuidado, a proteção, a formação ou o desenvolvimento.

\section{AS SINERGIAS}

As diferentes dimensões que vêm sendo trabalhadas pelos agentes não podem ser analisadas isoladamente; na realidade elas ocorrem de forma simultânea e em muitos casos contribuem umas com as outras. Deutsch, DuBois e Hirsch (2011) analisam esse aspecto apresentando o conceito de sinergias.

Para os autores, sinergias ocorrem quando diferentes dimensões contribuem umas com as outras e potencializam-se nos processos educativos. Fazendo estudos sobre programas de Educação Integral nos Estados Unidos, os autores exemplificam a sinergia com estudos de caso de diversos participantes desses programas. Em um dos casos, um dos alunos demonstra bastante interesse pela oficina de basquete. Ele se torna bastante habilidoso na prática e o educador começa a lhe pedir ajuda para ensinar outros alunos. A dimensão de formação de uma habilidade se torna a valorização de uma postura de liderança e trabalho em grupo. Em uma conversa, esse aluno diz ao mesmo educador que está indo mal na escola. O educador, então, traz o exemplo do basquete, dizendo que se ele consegue ir bem no basquete, ele pode ser bem-sucedido na escola também. O educador utiliza a habilidade do aluno para motivá-lo a persistir na escola. Esse relato é um típico exemplo de como uma dimensão contribui com outras e como por meio do incentivo a uma habilidade outras vão sendo constituídas (DEUTSCH; DUBOIS; HIRSCH, 2011).

Nas observações realizadas em nossa pesquisa de campo, foi possível constatar que muitas vezes os educadores investem um período de tempo para criar um vínculo afetivo com os alunos, para, então, começar a fazer cobranças acadêmicas e de responsabilidade. Os alunos são mais propensos a dar atenção e a obedecer àquelas pessoas com quem eles estabelecem vínculos afetivos. Da mesma forma, o vínculo afetivo tende a potencializar as orientações acadêmicas.

A dimensão aqui ressaltada é o modo como os diferentes aspectos aproximam-se, relacionam-se e interferem entre si, como 
se a partir de uma dimensão outras fossem trazidas à tona. Em uma das escolas pesquisadas, por exemplo, uma aluna, que no início do ano era bastante tímida, se torna a melhor jogadora de totó ${ }^{6}$ do Programa de Educação Integral. Ela é constantemente incentivada e exaltada pelos educadores, que valorizam seu desempenho. A partir da prática do totó, a aluna começou a se aproximar de outros alunos, ampliando a sua rede de relações.

Muitas instituições normalmente tendem a focar em apenas uma dimensão do desenvolvimento de crianças e jovens. A escola foca no acadêmico; a família, no afetivo; outras, na saúde; outras, ainda, na prevenção etc. Programas de Educação Integral podem enfocar uma diversidade de dimensões e potencializar ações conjuntas em uma perspectiva integral. Na perspectiva das sinergias, é, inclusive, difícil estabelecer uma separação entre as dimensões, pois em alguns momentos elas coexistem e se articulam em diferentes situações. Pudemos constatar que os Agentes Culturais pesquisados promovem, conscientemente ou não, uma sinergia em suas práticas educativas, contribuindo para a formação integral das crianças e dos jovens atendidos.

\section{OS NOVOS PROFISSIONAIS}

As novas concepções e propostas de Educação Integral vêm demandando a ressignificação das práticas educativas, das relações de aprendizagens e das identidades profissionais dos educadores. Tendemos a acreditar que os Agentes Culturais pesquisados estejam oferecendo alguns indícios de caminhos para novos modelos educacionais.

Como foi discutido, possivelmente por sua maior abertura na relação com seus alunos e por uma não vinculação a modelos prédefinidos de ensino, esses agentes vêm criando novas estratégias e posturas pedagógicas. É importante esclarecer que o reconhecimento de práticas docentes inovadoras, que surgem da relação com os educandos, não significa uma defesa do fim da formação docente, pelo contrário. Essas experiências devem ser sistematizadas, divulgadas e ressignificadas. O grande desafio que se coloca está justamente em um processo de formação docente que dê conta dessas novas demandas da educação.

Por fim, uma aprendizagem que se extrai das práticas dos agentes pesquisados está na centralidade da relação com os sujeitos educandos. A formação docente e a relação com o cotidiano escolar precisam dialogar de forma constante e complementar; nesse sentido, fazem-se necessárias experiências reflexivas que partam da realidade das escolas, dos educandos e de suas comunidades. 


\section{REFERÊNCIAS}

ARROYO, Miguel. O direito a tempos-espaços de um justo e digno viver. In: MOLL, Jaqueline. Caminhos da Educação Integral no Brasil: direito a outros tempos espaços educativos. Porto Alegre: Penso Editora, 2012.

BRASIL. Ministério da Educação. Secretaria de Educação Continuada, Alfabetização e Diversidade (SECAD). Centro de Estudos e Pesquisas em Educação, Cultura e Ação Comunitária. Diretoria de Educação Integral, Direitos Humanos e Cidadania (DEIDHUC). Educação integral/ educação integrada e (m) tempo integral: concepções e práticas da educação brasileira: mapeamento das experiências de jornada escolar ampliada no Brasil: estudo qualitativo. Brasília, 2009. Disponível em: < http://portal.mec.gov.br/index.php?option=com docman\&task $=$ doc_download\&gid=8199\&Itemid=>. Acesso em: 07 ago. 2014.

CHARLOT, Bernard. Da relação com o saber: elementos para uma teoria. Porto Alegre: Artmed, 2000.

CARVALHO, Levindo Diniz; DAYRELL, Juarez; GEBER, Saulo. Os jovens educadores em um contexto de educação integral. In: MOLL, Jaqueline (Org.). Caminhos da Educação Integral no Brasil. Porto Alegre: Penso, 2012, p. 157-171.

DAYRELL, Juarez; JESUS, Rodrigo Ednilson de. A exclusão de jovens de 15 a 17 anos no ensino médio no Brasil: desafios e perspectivas. Belo Horizonte; UFMG, 2013. 132p.. Relatório de pesquisa. mimeo.

DAYRELL, Juarez; LEÃO, Geraldo; REIS, Juliana Batista dos. Jovens olhares sobre a escola do ensino médio. Cadernos CEDES, São Paulo: Cortez; Campinas: CEDES, v. 31, n.1, p. 253-273, maio-ago. 2011a.

DAYRELL, Juarez; LEÃO, Geraldo; REIS, Juliana Batista dos. Juventude, projetos de vida e ensino médio. Educaşão \& Sociedade, São Paulo: Cortez; Campinas: CEDES, v. 32, n.1 p. 1067-1086 out-dez 2011b.

DEUTSCH, N.; DUBOIS, D.; HIRSCH, B. J. After-school centers and youth development: case studies of success and failure. New York: Cambridge University Press, 2011.

DUBET, François. El declive de la institución: profesiones, sujetos e individuos en la modernidad. Barcelona: Gedisa Editorial, 2006.

EVARISTO, Macaé Maria et al. Escola Integrada: novos tempos, lugares e modos para aprender. In: MOLL, Jaqueline. Conceitos e pressupostos: o que queremos dizer quando falamos de educação integral? TV Escola - Salto para o Futuro, Brasília, ano 18, boletim 13, p. 20-25, 2008.

GAUTHIER, Clermont et al. Por uma teoria da pedagogia: pesquisas contemporâneas sobre o saber docente. Ijuí: Editora Unijuí, 2006.

GLADWELL, Malcolm. Outliers: the story of success. New York: Little, Brown and Company, 2008.

GUARÁ, Isa Maria F. Rosa. Articulação de projetos e espaços de aprendizagem, 2007. Disponível em: $<$ http://www.promenino.org.br/ servicos/biblioteca/articulacao-de-projetos-e-espacosde-aprendizagem-1>. Acesso em: 1 out. 2014. (Biblioteca Fundação Telefonica Promenino).

HEATH, S. B. Dimensions of language development: lessons from older children. In: MASTEN, A. S. (Ed.). Cultural processes in child development. the Minnesota symposium on child psychology. Mahwah, NJ: Erlbaum, 1999.

HIRSCH, B. A place to call home: after-school programs for urban youth. Washington, DC: American Psychological Association; New York: Teachers College Press, 2005. 
KELLER, T. E. The stages and development of mentoring relationships. In: DUBOIS, D. L.; KARCHER, M. J. (Ed.). Handbook of youth mentoring. Thousand Oaks, CA: Sage, 2005.

KRAJCIK, Joseph S.; BLUMENFELD, Phyllis C. Project-based learning. In: SAWYER, R. Keith. The Cambridge Handbook of the Learning Sciences. Cambrige: Cambridge University Press, 2012.

LARSON, R. Youth organizations, hobbies, and sports as developmental contexts. In: SILBEREISEN, R. K.; TODT, E. (Ed.). Adolescence in context: the interplay of family, school, peers, and work in adjustment. New York: Springer-Verlag, 1993.

LARSON, R. Toward a psychology of positive youth development. American Psychologist, Washington, v. 55, n. 1, p. $170-183$, jan. 2000.

LAVE, Jean; WENGER, Etienne. Situated Learning. Cambridge: Cambridge University Press, 1991. MOLL, J. Caderno Educação Integral. Brasília: MEC-SECAD, 2008. (Série Mais Educação).

MURNANE, R.; LEVY, F. Teaching the new basic skills: principles for educating children to thrive in a changing economy. New York: Free Press, 1996.

NAKKULA, M. J.; HARRIS, J. T. Assessment of mentoring relationships. In: DUBOIS, D. L.; KARCHER, M. J. (Ed.). Handbook of youth mentoring. Thousand Oaks, CA: Sage, 2005.

RHODES, J. E. The critical ingredient: caring youth-staff relationships in afterschool settings. In: NOAM, G. G. (Ed.). After-school worlds: creating a new social space for development and learning. San Francisco: Jossey Bass, 2004.

ROBINSON, Ken. Out of our minds: learning to be creative. Westford, MA: Courier Westford, 2011.

SANTOS, B. S. Para uma sociologia das ausências e uma sociologia das emergências. Revista Crítica de Ciências Sociais, n. 63, p. 237-280, out. 2002.

SAWYER, R. Keith. The Cambridge Handbook of the Learning Sciences. Cambrige: Cambridge University Press, 2012.

TARDIF, Maurice. Saberes docentes e formaşão profissional. Rio de Janeiro: Vozes, 2002.

TEIXEIRA, Inês A. Castro. Da condição docente: primeiras aproximações teóricas. Educação e Sociedade, Campinas, v. 28, n. 99, p. 426-43, maio/ago. 2007.

\section{NOTAS}

${ }^{1}$ É importante pontuar que a perspectiva que iremos adotar neste texto não remete a todos os educadores que vêm atuando no contexto de Educação Integral, mas sim a um determinado perfil que acreditamos ser promissor e que detalharemos ao longo do artigo.

${ }^{2}$ Neste texto utilizaremos o termo Agentes Culturais para nomear os educadores dos programas de Educação Integral. Mais do que uma identificação com a terminologia, a escolha se dá por essa ser a nomenclatura adotada pelo Programa Escola Integrada da Prefeitura de Belo Horizonte - MG, programa em que temos concentrado parte de nossas investigações. No texto, ao referirmos ao Agente Cultural, estaremos nos referindo sempre àqueles que participaram da nossa pesquisa.

${ }^{3}$ A pesquisa de doutorado se intitula "As práticas educativas desenvolvidas por agentes culturais em programas de Educação Integral" e vem sendo desenvolvida no Programa de Pós-Graduação da Faculdade de Educação da Universidade Federal de Minas Gerais (UFMG). Nela foram pesquisados seis Agentes Culturais de duas escolas municipais situadas na periferia de Belo Horizonte durante o ano de 2013. 
${ }^{4}$ É importante ressaltar que, apesar de não ser foco desta análise, a relação entre pares também ocupa importância central na formação e socialização de crianças e jovens.

${ }^{5}$ Em um estudo comparado, temos feito uma revisão bibliográfica de experiências de Educação Integral nos Estados Unidos e dos agentes educadores responsáveis por essas ações (DEUTSCH; DUBOIS; HIRSCH, 2011). Buscaremos trazer alguns exemplos dessas experiências para enriquecer nossa análise.

${ }^{6}$ Totó é um jogo de madeira que simula o futebol.

Recebido: 26/06/2015

Aprovado: 15/08/2015

Contato:

Saulo Pfeffer Geber

Rua Teixeira Coelho, 333/51B

Curitiba |PR |Brasil

CEP 80.420-150 